\title{
VIOLÊNCIA INTRAFAMILIAR: ANÁLISE DA HISTÓRIA DE VIDA DE MÃES AGRESSORAS E TOXICODEPENDENTES NO CONTEXTO DA FAMÍLIA DE ORIGEM ${ }^{1}$
}

\author{
Daniela Borges Bittar², Ana Márcia Spanó Nakano³
}

\footnotetext{
${ }^{1}$ Artigo escrito a partir da dissertação intitulada - Violência intrafamiliar: um estudo com mães agressoras usuárias de álcool e drogas, Programa de Enfermagem em Saúde Pública, Mestrado em Ciências, Escola de Enfermagem de Ribeirão Preto (EERP) da Universidade de São Paulo (USP), 2009.

${ }^{2}$ Mestre em Ciências. Enfermeira especialista em Obstetrícia e Neonatologia pela EERP/USP. São Paulo, Brasil. E-mail: danielabbittar@yahoo.com.br

${ }^{3}$ Doutora em Enfermagem. Professora Livre Docente do Departamento de Enfermagem Materno-Infantil e Saúde Pública da EERP/USP. São Paulo, Brasil. E-mail: nakano@eerp.usp.br
}

RESUMO: Pesquisas nacionais e internacionais apontam a magnitude da violência intrafamiliar, mesmo que subestimada, sendo que alguns estudos identificam a mãe como principal agressora dos filhos. Buscou-se, nesse estudo, identificar os motivos que levam mulheres que vivem em contextos de álcool, drogas e violência, à agressão de seus filhos. A abordagem é qualitativa e, para a coleta de dados, utilizou-se a entrevista e a história de vida tópica. Através da análise de conteúdo, modalidade temática, depreendemos das falas das entrevistadas três categorias temáticas centrais: Convivendo com perdas: “...eu fiquei pro mundo"; Convivendo com alcoolismo, pobreza e violência em família; Convivendo com afetos e desafetos. Identificamos que o contexto familiar e social em que viveram as mulheres durante seu processo de socialização, na família de origem, reúne fatores que contribuem para manifestar atos de violência contra os filhos.

DESCRITORES: Violência doméstica. Alcoolismo. Transtornos relacionados ao uso de substâncias. Enfermagem.

\section{DOMESTIC VIOLENCE: LIFE HISTORY ANALYSIS OF AGGRESSIVE MOTHERS USERS OF ALCOHOL AND DRUGS IN THE CONTEXT OF THEIR ORIGINAL FAMILIES}

\begin{abstract}
National and international research points to the magnitude of domestic violence, even underestimated, and some studies have identified the mother as the main aggressor of their children. We aimed in this study to identify the reasons why women who live in contexts of alcohol, drugs, and violence are aggressive with their children. The approach is qualitative, and data was collected using interviews and topical life histories. Through thematic content analysis, three central themes were inferred from the words of those interviewed: Living with loss: "... I was left to the world"; Living with alcoholism, poverty, and violence in families; and Living with affection and the lack of affection. We identified that the family and social context in which the women lived during their process of socialization in their original family home unites factors that contribute to manifest acts of violence against their children.
\end{abstract}

DESCRIPTORS: Domestic violence. Alcoholism. Substance-related disorders. Nursing.

\section{LA VIOLENCIA DOMESTICA: UN ANÁLISIS DE LA HISTORIA DE VIDA DE LAS MADRES AGRESORAS Y DROGADICTAS EN EL CONTEXTO DE LA FAMILIA DE ORIGEN}

RESUMEN: Investigaciones nacionales e internacionales muestran la magnitud de la violencia doméstica, aunque es subestimada, y algunos de esos estudios han identificado a la madre como el principal agresor de sus hijos. Se busca en este estudio identificar las razones por las que mujeres que viven en contextos de alcohol, drogas y violencia agreden a sus hijos. El enfoque es cualitativo. Para la recolección de los datos se utilizó la entrevista y la historia de vida tópica. A través del análisis de contenido temático se deduce de las palabras de los entrevistados tres temas centrales: Viviendo con la pérdida: “... Llegué al mundo", Viviendo con alcoholismo, pobreza y violencia en familia; Viviendo con afecto y desafecto. Se identificó que el contexto familiar y social en que vivían las mujeres durante su proceso de socialización en el hogar familiar reúne factores que contribuyen a los actos manifiestos de violencia contra sus hijos.

DESCRIPTORES: Violencia doméstica. Alcoholismo. Trastornos relacionados con sustancias. Enfermería. 


\section{INTRODUÇÃO}

O Relatório Mundial sobre Violência e Saúde ${ }^{1}$ tornou público e mundial o problema da violência, ampliando o debate e permitindo a construção de referências para os diversos movimentos regionais. De outro lado, valoriza e resignifica esse problema, além de conferir um todo à problemática: unifica-se a violência enquanto questão a ser enfrentada, ao mesmo tempo em que se definem as distintas violências enquanto diversidades dessa questão plural.

A violência não é uma ocorrência exclusiva de determinada classe, faixa etária ou população, entretanto, certos grupos da sociedade, como mulheres, crianças e adolescentes e idosos são prioritariamente vitimizados.

No Brasil, estima-se que $20 \%$ das crianças e adolescentes sejam, hoje, vítimas de alguma forma de violência, ${ }^{2}$ mas não há pesquisas em âmbito nacional que tenham avaliado a extensão da violência intrafamiliar praticada contra indivíduos nessa faixa etária.

Há cerca de três décadas, vem sendo estudada a violência intrafamiliar, no nosso país, cometida pela família ou responsável, tanto pela magnitude, como pelas repercussões do problema. ${ }^{3}$

Várias pesquisas apontam para as grandes proporções com que a violência ocorre na infância, apesar de subestimada oficialmente em todo o mundo. ${ }^{4-5}$ No que diz respeito aos agressores, um estudo verificou que a mãe foi o agressor que contribuiu com a maior prevalência para a negligência $(60,7 \%)$; o pai contribuiu com $37,6 \%$, o padrasto com $24,3 \%$ e outros familiares com $25,7 \%{ }^{6}$

A respeito da violência praticada pelas mães, considera-se que as agressões físicas e psicológicas são remanescentes de uma cultura que compreende os castigos ou punições corporais e a desqualificação moral ou a humilhação da pessoa como recursos de socialização e práticas educativas. ${ }^{7}$ Autores concordam que a violência intrafamiliar é frequentemente justificada pelos agressores como forma de educar e corrigir transgressões de comportamento. ${ }^{7-9}$

O espaço de interação entre mães e filhos, em seu contexto de vida, pode ser capaz de revelar as multiplicidades de fatores que favorecem a expressão da violência: pobreza, relações conflitantes do casal, uso de álcool e drogas, vivência de violência conjugal na infância ou ter sofrido abuso quando criança. A este respeito considera-se que a tendência atual dos pesquisadores é de considerar a interação de diferentes fatores pessoais, situacionais e socioculturais combinando-se para provocar o abuso. ${ }^{10}$ Assim, como fatores pessoais do agressor, destacam: ter presenciado violência conjugal quando criança, ter sofrido abuso quando criança e consumo de bebidas alcoólicas e/ou drogas. Como fatores socioculturais, destaca-se a pobreza, dentre outros.

A toxicodependência das mulheres se constitui em um dos fatores que favorecem a expressão da violência, através de agressividade e atitudes negligentes com os filhos ${ }^{11}$; realidade esta, que temos nos deparado atuando junto a famílias de crianças e adolescentes em abrigamento e/ou situação de violência, que se constituem no universo empírico desta pesquisa.

No espaço de atuação do projeto denominado "Intervenções Breves para pessoas que abusam de álcool e drogas", instituído em Jardinópolis-SP, junto à Fundação Projeto Marcenaria da Música de Jardinópolis (PROMAR), foi aberta a possibilidade de aproximação de famílias que se encontravam sob intervenção judicial por violência intrafamiliar contra crianças e adolescentes. Através de equipe multidisciplinar eram realizadas reuniões semanais do grupo que integrava membros de famílias de crianças e adolescentes em abrigamento ou em situação de violência, quando se discutiam temas educativos diversos.

A família é reconhecidamente fundamental no trabalho de proteção integral à crianças e adolescentes. Quando há necessidade de afastamento da família, os esforços devem acontecer para que a reintegração se dê no menor tempo possível e, especialmente, para que as referências familiares não sejam perdidas. Para tanto, deve-se buscar o fortalecimento e a manutenção dos vínculos afetivos entre o abrigado e sua família. Assim, pais, mães e responsáveis poderão desenvolver as condições para receber seus filhos de volta, superadas as dificuldades que determinaram o afastamento.

Frente a essa realidade, entendemos que cabe aos profissionais dar suporte aos pais, enfatizandose nesta pesquisa a mãe enquanto principal agressora, que também requer ser cuidada, ajudando-a a encontrar caminhos para que recupere sua dignidade e respeitabilidade.

Importante estratégia nesta direção é conhecer a realidade de vida familiar e social destas mulheres para dar subsídios ao trabalho de recuperação dos vínculos mãe e filho em seu contexto familiar atual. Nesse sentido é que tomamos como objeto de estudo o contexto familiar e social em que essas mulheres viveram e foram criadas, em 
termos dos motivos que contribuíram para a manifestação do ato de violência contra o filho, tendo por base seus relatos de história de vida.

\section{OBJETIVO}

Identificar os motivos que levam mulheres, que vivem em contextos de álcool, drogas e violência, à agressão de seus filhos.

\section{TRAJETÓRIA METODOLÓGICA}

Para a compreensão do objeto de estudo, optou-se pela abordagem qualitativa. O recorte empírico do estudo foi dado por saturação, sendo composto por dez mulheres, mães, maiores de 18 anos, as quais viviam em um contexto de álcool, drogas e violência, integrantes do projeto supracitado, instituído em Jardinópolis-SP, junto à Fundação PROMAR. As mulheres foram entrevistadas aleatoriamente de acordo com a assiduidade às reuniões do projeto. Houve sucessivas inclusões de sujeitos, até que se pôde estabelecer uma análise adequada do problema.

O projeto foi criado após constatação em trabalho científico de que os casos de violência intrafamiliar que chegavam ao Poder Judiciário na Comarca de Jardinópolis, mesmo pós-intervenção judicial, continuam reincidentes, sendo que o município não dispunha de um núcleo de atenção aos usuários de álcool e drogas. ${ }^{12-13}$ Tais "Intervenções breves" possuíam como objetivos: recuperar os alcoolistas e/ou dependentes químicos, reintegrando-os às suas famílias e à sociedade; e promover a transformação e o crescimento pessoal, através da mudança de estilo de vida, levando-os a vencer suas próprias limitações.

A coleta de dados foi realizada no período de fevereiro a junho de 2009, sendo utilizada a história de vida tópica e a observação livre do ambiente relacional - interação mãe-filho durante as reuniões com o grupo. A entrevista foi aplicada pela própria pesquisadora, através de um roteiro norteador (construído pela pesquisadora) e gravada. Tanto a entrevista quanto a observação da relação mãe-filho, registrada em diário de campo, foram consentidas pelas informantes.

Utilizamos, para o tratamento dos dados, a técnica de análise de conteúdo, modalidade temática ${ }^{14}$, cujas etapas são: a pré-análise (fase de organização e sistematização das idéias), a exploração do material (fase em que os dados brutos do material são codificados para se alcançar o núcleo de compreensão do texto), e o tratamento dos resultados obtidos e interpretação (em que o investigador propõe suas inferências e realiza suas interpretações de acordo com o quadro teórico e os objetivos propostos).

Salientamos que a pesquisa foi realizada após a aprovação do Comitê de Ética em Pesquisa da Escola de Enfermagem de Ribeirão Preto, protocolo de aprovação $n^{\circ}$. 0946/2008 e, com o objetivo de garantir o anonimato dos relatos, identificamos os sujeitos por letras, S1, S2, S3... S10, na apresentação dos resultados.

\section{RESULTADOS E DISCUSSÃO}

A partir dos dados coletados, por meio da técnica de história de vida tópica e da observação livre do ambiente relacional, caracterizamos, primeiramente, as mulheres participantes, para depois, apresentar a análise do conteúdo das entrevistas.

\section{Perfil das mães que manifestam atos de violência contra seus filhos}

As dez mulheres entrevistadas neste estudo apresentavam uma média de idade de 35 anos. Quanto à ocupação, 80\% eram do lar, ou seja, a grande maioria dessas mulheres não possuía atividade remunerada. Em relação à escolaridade, cerca de $70 \%$ das entrevistadas cursaram apenas ensino fundamental incompleto e $20 \%$ delas eram analfabetas, o que significa que $90 \%$ das mulheres possuíam baixa ou nenhuma escolaridade.

No que diz respeito ao estado civil, 50\% eram casadas ou possuíam relação estável, 10\% eram solteiras e $40 \%$ separadas. Nos relatos das mulheres, percebemos um grande número de famílias reconstituídas ou recompostas.

A renda familiar variou de zero a $\mathrm{R} \$ 500,00$, sendo que $90 \%$ dos sujeitos referiram viver com menos de um salário mínimo. Quando se analisou o número de filhos das mulheres, foi verificada uma média de cinco filhos vivos por mulher, havendo uma variação de um a 11 filhos. É relevante colocar que apenas uma mulher possuía um único filho, e relatou ter abortado cinco ou seis vezes, sendo que estava grávida no momento da entrevista. Referiu que grande parte dos abortos aconteceram devido a espancamento pelo parceiro.

Nas distintas trajetórias de vida das mulheres entrevistadas, em suas famílias de origem, encontramos pontos em comum que retratam suas vivências quando crianças, sendo eles: a grande 
maioria conviveu com perdas, situações de alcoolismo e violência, afetos e desafetos, os quais estão detalhados nas categorias temáticas, a seguir.

\section{Convivendo com perdas: "... eu fiquei pro mundo"}

Em suas famílias de origem, as mulheres entrevistadas sofreram inúmeras perdas de familiares próximos, entes queridos, como a mãe ou o pai, acarretando desestruturação da família nuclear - aquela formada por pai, mãe e filhos do casal. Tais perdas podem estar relacionadas à morte desses familiares, ou mesmo a uma separação ocorrida por inúmeros motivos.

Morava com minha madrinha, meu pai morreu com 30 anos, minha mãe é viva e mora em Santa Rita do Passa Quatro. [...] eu vim pra cá porque minha mãe não tinha condição de criar nós, quatro irmãos, aí ela nos deu pra minha madrinha (S2).

Identifica-se, através das falas destas mulheres, o valor de pai como provedor, que se faz sentir pelas dificuldades financeiras que a família passa a viver e enfrentar diante da falta da tutela paterna, que se apresenta como fator desagregador da família.

Os significados atribuídos pelas mulheres à ausência da figura paterna seguem a visão tradicional dos papéis parentais em nossa sociedade, em que o papel de provedor é exercido pelo homem como necessário nas camadas populares. ${ }^{15}$ Entretanto, os mesmos autores sinalizam que tal papel é insuficiente, dado que existem outras tarefas consideradas próprias de pai: educar, ajudar nos deveres, brincar...

Referências às perdas da figura materna também se mostraram evidenciadas nas falas destas mulheres:

[...] até cinco anos eu morei com minha mãe e meu pai, depois ela morreu [...]. Meu pai também deixava nós, ficávamos sozinhos a noite inteira. Aí o denunciaram, que não podia; já tinha arrumado até uma família pra dá nós embora (S9).

[...] quando a minha mãe era viva eu morava com ela. Quando ela morreu eu tinha oito anos. Morreu meu pai e minha mãe. Aí eu fiquei pro mundo (S10).

Enquanto os homens são reconhecidamente importantes à sobrevivência econômica da família, as mulheres, como mães, são agentes decisivos na esfera da reprodução social, pois são as que mais participam da educação, transmitindo aos filhos as ideologias vigentes na sociedade. ${ }^{16}$
Estudos apontam os efeitos nocivos sobre a formação da criança quando observada num processo de separação dos pais e, em especial, da mãe. ${ }^{17-19}$ Ressalta-se a importância do afeto na relação mãe-filho no aparecimento e desenvolvimento da consciência do bebê e a participação vital que a mãe tem ao criar um "clima emocional favorável", sob todos os aspectos, ao desenvolvimento da criança. Segundo o autor, são os sentimentos maternos que criam esse clima emocional que confere ao bebê uma variedade de experiências vitais muito importantes por estarem "interligadas, enriquecidas e caracterizadas pelo afeto materno" ${ }^{17: 99}$

$\mathrm{Na}$ ausência da figura paterna e materna várias são as pessoas que podem oferecer suporte à família e ao indivíduo, promovendo, assim, uma melhoria na qualidade de vida daqueles beneficiados. ${ }^{20-22}$ Dentre elas, destacam-se os próprios membros familiares, outros parentes da família extensa (avós, tios, primos), amigos, companheiros, vizinhos e profissionais, que podem auxiliar de diversas maneiras. Tal fato pode ser observado no relato das entrevistadas deste estudo.

Eu fugi com uma amiga minha pra casa da minha tia... depois eu voltei de novo e fui morar com uma mulher chamada Tereza e fiquei com ela dos nove anos até meus 16 anos... a Tereza é minha mãe de criação. Como eu não dei certo com minha avó nem com minha tia eu fui morar com a Tereza. Ela sempre me tratou bem (S6).

Pode-se dizer que a separação dos pais não é, em si, necessariamente, um fator a perturbar o desenvolvimento da criança, mas essa separação aliada à ausência de condições favorecedoras do seu desenvolvimento, é responsável por estresse e prejuízo no desenvolvimento da criança, além de dificultar sua vivência com outros membros da família de forma sólida e contínua.

\section{Convivendo com alcoolismo, pobreza e violência em família}

As falas das mulheres retratam as condições desfavoráveis vivenciadas durante toda a infância e adolescência, incluindo a presença de álcool/ drogas em casa e vivências de pobreza e violência, deixando evidenciar famílias em situação de degradação.

Eu tinha vergonha de contar para os meus amigos, né, do meu pai. Meu pai bebia, bebia muito, tipo alcoólatra [...]. Quando ele bebia, ficava agressivo, batia na gente e na minha mãe, mas teve uma vez que nós não o deixamos bater nela não (S3). 
Meu pai fumava e bebia pinga também [...] chegou uma época que ele jogava comida fora, a gente tinha que esperar ele dormir pra poder entrar pra dentro, pra gente comer [...]. Ele não era ruim, a bebida é que o deixava desse jeito (S8).

Fomos morar debaixo de uma mangueira, lá na Vila, lá em cima. Nós íamos à cidade com latinha e pedia comida e levava tudo pra debaixo da mangueira (S10).

Aspectos de degradação familiar podem ser apreendidos nos relatos sobre a ocorrência da violência intrafamiliar como parte do cotidiano das famílias de origem destas mulheres. A associação do alto consumo do álcool e práticas de violência tem sido objeto de estudos de autores. $\mathrm{O}$ consumo de álcool ou drogas em larga escala no Brasil, principalmente por homens, manifesta-se em mudanças de humor expondo ao maior risco de praticar violência, principalmente contra as mulheres. ${ }^{23}$

Sobre a associação entre pobreza e violência, concordamos que o aumento dos níveis de miséria constitui fator importante para o crescimento da violência. No entanto, partilhamos da idéia de que tal associação indiscriminada pode gerar uma criminalização da pobreza, colocando segmentos sociais inteiros como suspeitos ou na mira de permanentes julgamentos prévios. ${ }^{24}$

A vivência de presenciar a violência conjugal se mostra como fato que marcou a infância dessas mulheres. Na dinâmica das relações conjugais identificam-se pólos de subordinação e dominação. A divisão interna de papéis admite uma distribuição desigual de privilégios, direitos e deveres dentro do ambiente doméstico, setor em que se definem assimetrias de poder calcadas em diferenças de gênero.

Abaixo, relacionamos uma fala, em que a mulher entrevistada coloca que presenciou violência conjugal entre seus pais substitutos, durante sua infância.

Meu padrinho brigava com minha madrinha. Ele chegava a bater nela, ele bebia muito. Já entrei no meio de briga deles. Eu era criança e falei "pára, tio, de brigar com a tia". Ele a ameaçava. Pus um remédio na comida dele, que ele dormiu. Tem marido e mulher que briga e quebra tudo [...] (S2).

Observamos que, dentre as causas de comportamentos violentos, além do uso de álcool e drogas, que se mostrou predominante neste grupo, o dinheiro e o ciúme também foram considerados fatores causais de conflitos conjugais, manifestando-se em atos violentos.
[...] meu pai brigava muito com a minha mãe, por ciúmes das duas partes [...]. Meu pai agredia minha mãe e eu via. Eu era muito pequena, mas eu lembro mais ou menos: uma vez que ele bateu nela, porque ele saiu e ficou o dia inteiro fora de casa, ele tinha recebido. Ela ficou nervosa e quando ele chegou, pra agradar ela, ele chegou com uma manga e ela tava brava e ele esfregou a manga no rosto dela. Eles começaram a brigar e ele bateu nela (S3).

À respeito dos fatores desencadeantes da violência, estudo sobre as características gerais das famílias de crianças e adolescentes vitimizados observam que, segundo os membros da família, 58\% acreditam que os conflitos do casal contribuíram para desencadear a violência, 51\% acreditam que foram as características próprias da criança ou do adolescente, $49 \%$ atribuem ao histórico de vida dos pais, $40 \%$ associam a violência ao fato de ter dificuldades em colocar limites para seus filhos, $32 \%$ afirmam que o alcoolismo foi um dos fatores desencadeantes, 25\% à fatores socioculturais, 25\% à falta ou excesso de trabalho, $21 \%$ à outros fatores e $9 \%$ à outros tipos de drogas. ${ }^{25}$

A maioria das entrevistadas se lembra da infância como um período difícil devido às agressões físicas, sexual e psicológicas sofridas.

[...] ele amarrava nós no fogão pra não escapar, sem blusa. Eu, com 12 anos de idade, tava começando a criar peito. Uma, porque não tinha roupa, e outra, porque ele tirava nossa roupa pra bater em nós (S7).

As marcas deixadas pela violência intrafamiliar na infância são, muitas vezes, subestimadas, por considerar seu impacto temporário e desaparecer no decorrer do desenvolvimento infantil. Entretanto, a agressão contra a criança/adolescente deve ser reconhecida como um sério problema da infância e mesmo que crianças vitimizadas sejam retiradas de suas casas, os efeitos da experiência vivida repercutirão por toda a vida. Tal condição pode ser observada pelas lembranças que estas mulheres trazem de seu passado de sofrimento.

Nós fomos criados numa infância muito ruim. Ele bateu muito em nós (S7).

Sobre a violência sexual, identificamos, na fala da entrevistada S7, a indignação com a atitude do padrasto, o qual abusou sexualmente de sua irmã, dos sete aos 14 anos, e também tentou abusar dela.

[...] minha outra irmã, que hoje é doente, vive inválida em cima da cama, por causa de estupro. Foi estuprada por ele mesmo, por esse homem, pelo próprio padrasto. Começou com sete anos. [...] já era um homem 
velho, com seus quase 40, né [...]. Quando ela fez 14 anos, estava grávida, ficou de sete a 14 anos sendo abusada, sem poder falar nada (S7).

Dada à exposição desses eventos de tamanha magnitude é que a violência sexual adquiriu um caráter endêmico e tornou-se um problema de saúde pública a ser enfrentado, não só por gestores, mas por toda a sociedade. ${ }^{26}$

Diante dessas situações, formas de enfrentamento podem ser identificadas na tentativa de fuga dessa realidade que cercava essas mulheres, colocando-as frente a decisões arriscadas e, por vezes, inconsequentes, mas que, naquele momento da vida, pareciam ser as únicas possíveis.

Eu enrolei minha vida com 13 anos. Precisei fugir com o namorado, pra não ser abusada por ele [o padrasto] dentro de casa. O meu namorado eu nem conhecia direito, porque a pessoa, pra viver com outra, tem que conhecer muito, né? Primeiro você tem que saber quem ele é, pra depois você casar (S7).

Questiona-se o quanto o contexto de vida foi decisivo na tomada de decisão, bem como o peso do modelo de ser mulher na família de origem, evidenciando um atravessamento intergeracional pelo processo de socialização, aliado a experiências singulares, no âmbito das relações familiares.

\section{Convivendo com afetos e desafetos}

A vivência de uma relação calorosa, íntima e contínua com a mãe ou mãe substituta permanente, ou seja, uma pessoa que desempenha, regular e constantemente, o papel de mãe, mostra-se essencial à saúde mental da criança. É essa relação complexa, rica e compensadora com a mãe, nos primeiros anos de vida, enriquecida de inúmeras maneiras, pelas relações com o pai e familiares, que a comunidade científica julga estar na base do desenvolvimento da personalidade e da saúde mental. ${ }^{18}$ Tal condição ideal está longe de ser a realidade das mulheres desse estudo, junto às suas mães, na infância.

Lembro-me que minha mãe vivia batendo em mim, porque eu era responsável pelos outros dois. Se os outros dois fizessem alguma coisa, era pra cima de mim que vinha. Ela me dava cintada, chinelada. Antigamente podia né, hoje em dia não pode (S4).

S4 relata sobre as agressões que sofria de sua mãe durante a infância, em razão da desobediência frente à ordem de cuidar dos irmãos. Também traz a idéia que perpassa nos momentos atuais de que agressões "corretivas" são atualmente proibidas, por se caracterizarem como violência física. Para além da discussão do corretivo, como forma de violência ou não, o que recomendam os estudiosos no assunto, é que as agressões físicas deixam marcas negativas em longo prazo, tornando-se evidentes as vantagens das práticas educativas sem punição corporal, tal como o diálogo. Esse, além de ajudar no desenvolvimento de habilidades sociais dos filhos, mantém uma dinâmica familiar com responsividade, afeto e comprometimento. ${ }^{27}$

Os reflexos em longo prazo podem ser apreendidos nas falas destas mulheres, que se lembram da figura materna com certa mágoa, o que se expressa em carência afetiva, negligência nos cuidados e em um relacionamento mãe-filha distante:

[...] eu não tenho muita lembrança boa da minha mãe não, tanto é que, pode ser pecado, mas eu não sinto muita falta dela [...]. Pra dizer a verdade, eu achava tão bom, tão gostoso quando ela me chamava de filha. Era muito raro, muito raro. Geralmente ela mandava, não pedia, sempre brava (S4).

A mãe é diferente, né, ela já batia, já dava uma sacudida. Tem mãe que não sai pegando pra bater, porque se pega pra bater [...]. Ela batia de cinta, espada de São Jorge, com a mão (S8).

As carências afetivas pontuadas por estas mulheres durante a infância têm reflexos futuros no desempenho de relações afetivas com os filhos, conforme apontam alguns estudos científicos. A ausência de afeto no relacionamento familiar durante a infância torna o desenvolvimento da identidade materna uma "auto" dificuldade, limitando a possibilidade de experiências positivas de contato físico, cuidado e socialização. Pouca estrutura psicológica para assumir a responsabilidade materna representa a origem dos conflitos, levando a uma falha no sentimento do papel materno. ${ }^{28}$

Um fato a ser considerado é que a proximidade da mãe com o filho parece favorecer a ocorrência de situações de dificuldades interpessoais, o que é comprovado em um estudoqueidentificou ser a mãe a maior agressora dos filhos no ambiente doméstico. ${ }^{25}$

A falta de habilidades sociais e os traços antissociais dos pais são considerados importantes fatores de risco familiar. Os traços antissociais maternos são os principais contribuintes para o desenvolvimento de interações coercitivas, as quais, em ambientes familiares, excluem e dificultam a utilização de técnicas positivas de motivação e guia na educação dos filhos. ${ }^{29}$

As marcas deixadas pela violência não são somente físicas, mas sequelas emocionais, podendo prejudicar o aprendizado, as relações sociais, 
e o desenvolvimento pleno, exercendo impacto em longo prazo, com repercussões na família e na sociedade. ${ }^{30}$

A este respeito, observa-se que o indivíduo que sofreu violência na infância ou não foi uma criança aceita, reconhecida ou desejada terá consequências que se refletirão no futuro, particularmente, na forma como irá tratar seus filhos. Isso não acontece de forma determinista, geralmente há recursos e fatores de proteção que medeiam os efeitos em cada caso. ${ }^{31}$

Relevante fator de proteção é a família que tem influência na possível ciclicidade da violência. A família ocupa a instância diferenciada quanto à proteção deste grupo etário, pois, é através do convívio e do cuidado - ou da sua ausência - que se projetam as relações e os valores sociais. Mediante a convivência afetiva, a criança e o adolescente podem assimilar, entre outros aspectos, tanto os múltiplos limites, quanto as diversas possibilidades de cooperação, de aceitação e tolerância, de alteridade e solidariedade.

\section{CONSIDERAÇÕES FINAIS}

As representações que significam e inscrevem a maternidade no corpo e na alma das mulheres, de serem afetivas, continentes e dóceis, nos colocam frente a uma visão incompreensível da violência que mães cometem contra seus filhos. Neste sentido, um importante passo para responder construtivamente diante de uma situação de violência contra a criança ou o adolescente é nos desvestirmos dos estigmas em relação às mães agressoras e buscar compreendê-las em suas trajetórias de vida, as quais as conformaram e conformam como mães, revelando características de indeterminação, ambiguidade e instabilidade frente a seus papéis sociais, entre eles, o materno.

Partimos de uma realidade comum a todas as mulheres do estudo: serem elas mães, agressoras, que vivem em um contexto de álcool, drogas e violência, seguidas pela justiça da Comarca de Jardinópolis-SP e participantes do projeto "Intervenções breves para pessoas que abusam de álcool e drogas".

A análise da história de vida dessas mulheres aponta para um perfil comum de mães agressoras: durante a infância e a adolescência, na família de origem, conviveram com perdas de entes queridos, situações de abuso de álcool/drogas e violência, afetos e desafetos. Situações estas que se refletiram no contexto familiar atual, no qual se observa certa ciclicidade de desestruturação familiar.
O contexto familiar e social, em que viveram as mulheres entrevistadas, durante seu processo de socialização, reúne motivos que contribuem para dissociações importantes no desempenho de seus papéis maternos, levando as mulheres/mães a cometer atos de violência contra de seus filhos.

Embora se parta do princípio de que o uso do álcool e demais drogas é uma situação comum a todas as mulheres/sujeitos deste estudo, podemos dizer que não somente esse uso pode ser considerado como fator pessoal de desajustes nas relações interpessoais, particularmente, entre mães e filhos. Chamamos a atenção para as experiências vivenciada por estas mulheres na infância, ou seja, um passado marcado por desestruturação familiar, em que se somam perdas de entes queridos, situações de pobreza, uso de álcool/drogas na família e violência. Assim, evidencia-se como comum a essas mulheres, um ciclo vicioso de violência.

\section{REFERÊNCIAS}

1. Organização Mundial da Saúde. Relatório mundial sobre violência e saúde. Genebra (CH): OMS; 2002.

2. Minayo MCS. A difícil e lenta entrada da violência na agenda do setor saúde. Cad Saúde Pública. 2004 Mai-Jun; 20(3):646-7.

3. Azevedo MA. Contribuições brasileiras à prevenção da violência doméstica contra crianças e adolescentes. In: Westphal MF, organizador. Violência e criança. São Paulo (SP): Editora da Universidade de São Paulo; 2002. p. 125-35.

4. Martins CBG, Jorge MHPM. Child abuse: a review of the history and protection policies. Acta Paul Enferm. 2010 Abr; 23(3):423-8.

5. Mian M. World report on violence and health: what it means for children and pediatricians. Jornal de Pediatria, 2004 Out; 145:14-9.

6. Costa MCO, Carvalho RC, Bárbara JFRS, Santos CAST, Gomes WA, Sousa H L. O perfil da violência contra crianças e adolescentes, segundo registros de Conselhos Tutelares: vítimas, agressores e manifestações de violência. Ciênc Saúde Coletiva. 2007 Set-Out; 12(5):87-8.

7. Sacramento LT; Rezende MM. Violências: lembrando alguns conceitos. Aletheia. 2006 Dez; 24: 95-104.

8. Minayo MCS. O significado social e para a saúde da violência contra crianças e adolescentes. In: Westphal MF, organizador. Violência e criança. São Paulo (SP): Editora da Universidade de São Paulo; 2002. p. 95-11.

9. Silva LMP, Nascimento CAD, Silva IR, Guimarães, KN. Violência doméstica contra crianças e adolescentes. Brasília (DF): Ministério da Saúde; 2002. 
10. Day VP, Telles LE, Zoratto PH, Azambuja MR, Macado DA, Silveira MB. Violência domestica e suas diferentes manifestações. Rev Psiquiatria. 2003 Abr; 25(Suppl. 1):9-21.

11. Hochgraf PB, Brasiliano S. Treatment services for substance abuse that are responsive to gender. A brazilian experience with drug dependent women. In: United Nations Office on Drugs and Crime (UNODC). Substance abuse treatment and care for women: case studies and lessons learned. New York (US): United Nations Publication. 2004; p. 57-96.

12. Roque EMST. A violência na família contra crianças e adolescentes e a percepção dos operadores do direito, na comarca de Jardinópolis-SP [dissertação]. Ribeirão Preto (SP): Universidade de São Paulo, Escola de Enfermagem de Ribeirão Preto; 2001.

13. Roque EMST. Estudo das famílias de crianças e adolescentes, vítimas de violência, que sofreram intervenções da justiça, em comarca de vara única - Estado de São Paulo - Brasil [tese]. Ribeirão Preto (SP): Universidade de São Paulo, Escola de Enfermagem de Ribeirão Preto; 2006.

14. Minayo MCS. O desafio do conhecimento: pesquisa qualitativa em saúde. $9^{a}$ ed. São Paulo (SP): Hucitec; 2006.

15. Alatorre J, Luna R. Significados y prácticas de la paternidad en la ciudad de México. In: Fuller N, organizador. Paternidades en América Latina. Lima (PE): Fondo Editorial PUCP; 2000; p. 241-75.

16. Gomez, GQ. A maternidade sob a ótica da teoria pulsional. Ágora: Estudos em Teoria Psicanalítica [online]. 2007 Jul-Dez [acesso 2010 Dez 16]; 10(2):265-78. Disponível em: http://www.scielo. br $/$ scielo.php?script $=$ sci_arttext\&pid $=S 1516$ 14982007000200008\&lng=en\&nrm=iso.

17. Spitz RA. O primeiro ano de vida: um estudo psicanalítico do desenvolvimento normal e anômalo das relações objetais. São Paulo (SP): Martins Fontes; 1979.

18. Bowlby J. Cuidados maternos e saúde mental. São Paulo (SP): Martins Fontes; 1988.

19. Serralha CA. Winnicott com Gabrielle e seus pais. Nat Hum [online]. 2009 Jun [acesso 2010 Dez 16]; 11(1):149-64. Disponível em: http:// pepsic.bvsalud.org/scielo.php?script $=\mathrm{sci}_{\text {_ }}$ arttext\&pid $=S 1517=$ pt\&nrm $=$ iso.
20. Brito-Dias CMS. A importância dos avós no contexto familiar. Psicologia: teoria e pesquisa. 1994 Jan- Abr; 10: 31-40.

21. Soares MPG, Franco ALS, Carvalho AMA. Crianças que cuidam de irmãos com necessidades especiais. Psic: Teor e Pesq [online]. 2009 Mar [acesso 2010 Dez 16]; 25(1). Disponível em: http:/ / www.scielo. br/scielo.php?script=sci_art\&pid=iso.

22. Lewis M. Social development in infancy and early childhood. In: Osofsky JD, organizador. Handbook of infant development, New York (US): Wiley; 1987. p 419-93.

23. Rabelo, CJ. Violência contra a mulher, coesão familiar e drogas. Rev Saúde Pública. Dez 2007; 41(6):970-8.

24. Gomes R, Deslades SF, Veiga MM, Bhering C, Santos JFC. Por quê as crianças são maltratadas? Explicações para a prática de maus-tratos infantis na literatura. Cad. Saúde Pública. 2002 Mai-Jun; 18(3):707-14.

25. Brito AMM, Zanetta DMT, Mendonça RCV, Barison SZP, Andrade VAG. Violência doméstica contra crianças e adolescentes: estudo de um programa de intervenção. Ciênc Saúde Coletiva; 2005 Dez; 10: 143-9.

26. Ribeiro MA, Ferriani MGC, Reis JN. Violência sexual contra crianças e adolescentes: características relativas à vitimização nas relações familiares. Cad Saúde Pública. 2004 Mar-Abr; 20(2):456-64.

27. Weber LND, Viezzer AP, Brandenburg OJ. O uso de palmadas e surras como prática educativa. Estudos Psicol. 2004 Jul; 9: 227-37.

28. Brundenell I. A grounded theory of protecting recovery during transition to motherhood. Am Journal Drug Alcohol Abuse. 1997 Aug; 23(3):453-66.

29. Martins CBG, Jorge MHPM. Abuso sexual na infância e adolescência: perfil das vítimas e agressores em município do sul do Brasil. Texto Contexto Enferm. 2010 Abr-Jun; 19(2):246-55

30. Sanchez RN, Minayo MCS. Violencia contra crianças e adolescentes: questão histórica, social e de saúde. In: Ministério da Saúde (BR). Violência faz mal à saúde. Brasília (DF): Ministério da saúde; 2006.

31. Bringiotti MI. Las familias en "situación de riesgo": en los casos de violencia familiar y maltrato infantil. Texto Contexto Enferm. 2005 Nov; 14(Esp):78-85. 